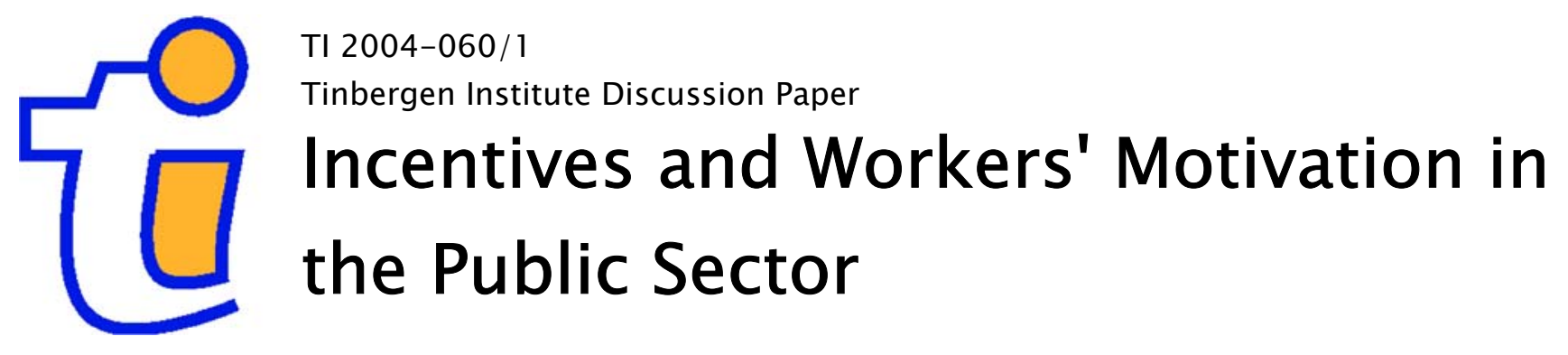

Josse Delfgaauw

Robert Dur

Faculty of Economics, Erasmus Universiteit Rotterdam, and Tinbergen Institute. 


\section{Tinbergen Institute}

The Tinbergen Institute is the institute for economic research of the Erasmus Universiteit Rotterdam, Universiteit van Amsterdam, and Vrije Universiteit Amsterdam.

Tinbergen Institute Amsterdam

Roetersstraat 31

1018 WB Amsterdam

The Netherlands

Tel.: $\quad+31(0) 205513500$

Fax: $\quad+31(0) 205513555$

Tinbergen Institute Rotterdam

Burg. Oudlaan 50

3062 PA Rotterdam

The Netherlands

Tel.: $\quad+31(0) 104088900$

Fax: $\quad+31(0) 104089031$

Most TI discussion papers can be downloaded at http:/ /www.tinbergen.nl. 


\title{
Incentives and Workers' Motivation in the Public Sector*
}

\author{
Josse Delfgaauw $^{\dagger}$ and Robert Dur ${ }^{\ddagger}$
}

August 14, 2006

\begin{abstract}
Civil servants have a reputation for being lazy. However, people's personal experiences with civil servants frequently run counter to this stereotype. We develop a model of an economy in which workers differ in laziness and in public service motivation, and characterise optimal incentive contracts for public sector workers under different informational assumptions. When civil servants' effort is unverifiable, lazy workers find working in the public sector highly attractive and may crowd out dedicated workers. When effort is verifiable, the government optimally attracts dedicated workers as well as the economy's laziest workers by offering separating contracts, which are both distorted. Even though contract distortions reduce aggregate welfare, a majority of society may be better off as public goods come at a lower cost.
\end{abstract}

JEL codes: H1, J3, J4, L3, M5

Keywords: Public Sector Labour Markets, Incentive Contracts, Work Ethics, Public Service Motivation.

${ }^{*}$ We gratefully acknowledge valuable comments and suggestions by two anonymous referees, the editor, Klaas Beniers, Laurent Franckx, Maitreesh Ghatak, Amihai Glazer, Pierre Koning, Clare Leaver, David Martimort, David Mitchell, Efraim Sadka, Alois Stutzer, Otto Swank, seminar audiences at Bocconi University (IGIER), University College London, University of Essex, University of Cologne, University of California, Irvine, University of Bergen, WZB Berlin, University of Amsterdam (AIAS and CREED), CPB Netherlands, and conference participants in Berlin (EPCS 2004), Munich (CESifo Area Conference on Public Sector Economics 2004), New Orleans (PC 2005), and Rotterdam (Conference on Incentives and Work Motivation in the Public Sector, 2005). We thank André Dickmann and Steven van der Walle for providing data. We gratefully acknowledge financial support from NWO, KNAW, and VSNU through a Vernieuwingsimpuls grant.

${ }^{\dagger}$ Tinbergen Institute, Erasmus University Rotterdam, P.O. Box 1738, 3000 DR Rotterdam, The Netherlands. E-mail: delfgaauw@few.eur.nl.

${ }^{\ddagger}$ Tinbergen Institute, Erasmus University Rotterdam, and CESifo, Munich. 


\section{Introduction}

Civil servants have a reputation for being lazy (Wilson, 1989). Jokes about civil servants' laziness and stories on bureaucratic errors abound. The lack of incentives in public organisations is supposed to attract workers who are most averse to exerting effort. This pessimistic view is also prominent in the economics literature. For several decades, the literature has identified civil servants as pursuing their narrow self-interest, usually being at odds with the interest of society (see Tullock, 1965, Downs, 1967, Niskanen, 1971, and Buchanan, 1978).

However, when citizens are asked about recent personal experience with civil servants, many tend to be satisfied with their performance (Katz et al., 1975, Goodsell, 1985). Surveys of workers and managers in the public sector also suggest that quite a few civil servants do not fit the stereotype. Instead, even when external incentives are weak or nonexistent, quite some civil servants appear to be highly motivated to provide a service to the community. ${ }^{1}$ Such 'public service motivation' of civil servants is also a central theme of a number of recent economic studies of public agencies (Francois, 2000, Prendergast, 2003, Glazer, 2004, Besley and Ghatak, 2005, and Delfgaauw and Dur, 2005b).

How to reconcile these seemingly opposing points of view? This paper develops a model with three types of workers: regular, lazy, and dedicated workers. Compared to regular workers, lazy workers have higher cost of effort in both the private and the public sector. Dedicated workers are endowed with a public service motivation and, therefore, to some extent enjoy exerting effort in a public sector job. Otherwise, dedicated workers are identical to regular workers. This public service motivation gives monopsony power to the government. We show that it is in the interest of a costminimising government to recruit, in addition to dedicated workers, lazy workers rather than regular workers, and to provide lazy workers with weaker incentives than private firms do.

Whereas we model the private sector as a competitive market in which workers are paid their full marginal product, the public sector is assumed to

\footnotetext{
${ }^{1}$ See chapter 2 in Le Grand (2003) for a review of the empirical literature on workers' motivation in the public sector. Other recent studies include Antonazzo et al. (2003) on nursing workers, Edmonds et al. (2002) on teachers, and Frank and Lewis (2004) on employees in these and several other areas of the public sector.
} 
be a single organisation whose objective is to produce a certain amount of public goods at minimum cost. This organisation, which we refer to as the public agency, attracts workers by offering one or more contracts specifying the wage and, if verifiable, required effort. The public agency can not observe workers' types and, hence, can not make the contracts contingent on worker type. Workers choose the contract that yields them the highest utility, provided that the private sector is not a better option.

We consider two cases: verifiable and unverifiable effort. When effort is unverifiable, the public agency prefers to hire either dedicated or lazy workers. We show that it may occur that the public agency prefers to attract only dedicated workers, but that it can not avoid hiring lazy workers as well. However, if desired public production is sufficiently large, the public agency wants to attract both dedicated and lazy workers, implying that the problem of nonexcludability of lazy workers is less severe.

When effort is verifiable and desired production in the public sector is sufficiently small, the public agency hires only dedicated workers, and extracts all motivational rents from these workers. This full rent extraction may not be possible if a second worker type is needed. Any rents dedicated workers obtain when they would choose the other type's contract can not be extracted by the public agency. Since a contract satisfying a lazy worker's participation constraint has lower wage and lower required effort than a regular worker's contract, a lazy worker's contract is less appealing to the dedicated workers. Therefore, the public agency can extract more motivational rents, and hence can attract dedicated workers at lower cost, if it attracts lazy workers rather than regular workers.

The public agency distorts both contracts in order to extract even more motivational rents. It offers lower-powered incentives to lazy workers than do private firms. This way, the lazy worker's contract becomes even less appealing to the dedicated workers. However, to keep production at the desired level, the public agency has to hire additional lazy workers, which is costly. These costs can be reduced by giving dedicated workers higherpowered incentives, above the level private firms would offer.

These contract distortions are cost-efficient, but reduce social welfare. If we impose that the public agency maximises social welfare rather than minimises cost, it does not distort the contracts of the workers. The public agency still prefers to attract dedicated workers, but if a second worker type 
is needed, it is indifferent between lazy and regular workers. Compared to a cost-minimising public agency, social welfare is higher. However, total cost of public goods production and, hence, taxes are also higher when the public agency maximises social welfare. Only dedicated workers benefit, whereas the utility of lazy and regular workers decreases as a result of higher taxes. When dedicated workers are a minority in society, politicians are likely to strive for cost-minimisation rather than for social welfare maximisation, so as to please the public at large.

While there exists quite some empirical evidence showing that a significant part of the civil work force has a public service motivation (see the references in footnote 1), there exists little evidence confirming the stereotype view that civil servants are lazy. It is important to note that our model does not necessarily imply that workers in the public sector are on average more lazy than workers in the private sector; nor does it imply that lazy workers are always more numerous in the public sector than in the private sector. ${ }^{2}$ Therefore, rather than comparing sectoral averages of workers' characteristics, Table 1 and 2 present data on workers who have moved from one sector to the other. Following Johnson (1978)'s model of 'job shopping' and Jovanovic (1979)'s model of turnover, we expect a worker to move in case of a mismatch between the worker's tastes or abilities and his job's attributes or requirements. In the context of our model, we thus predict regular workers to move from the public sector to the private sector, whereas lazy and dedicated workers move in opposite direction. We should therefore observe a lower proportion of lazy workers among workers who move from the public sector to the private sector than among workers who move from the private sector to the public sector. Table 1 reports data from the United States which are consistent with this prediction. We use the Wisconsin Longitudinal Study (WLS), a long-term study of a large sample of graduates from Wisconsin high schools in 1957, which contains data on people's first full-time civilian job since completing school, people's last job before retirement, as well as data on personality traits including the response to the statement "I see myself as someone who is lazy at times." While less than $40 \%$ of workers who move from the public sector to the private sector

\footnotetext{
${ }^{2}$ For instance, when there are many lazy workers in the economy, and the public sector is not too large, the majority of lazy workers will work in the private sector. Depending on the number of dedicated workers, workers in the public sector can be more lazy or less lazy on average than are workers in the private sector.
} 
agree with this statement, $50 \%$ of workers who move from the private sector to the public sector see themselves as lazy at times.

Table 1: Percentage of workers who agree with the statement "I see myself as someone who is lazy at times" (Wisconsin Longitudinal Study, 1957-1977 and 2003-2005 waves).

\begin{tabular}{l|ccc} 
& \multicolumn{2}{|c}{$\begin{array}{c}\text { Last job in the } \\
\text { private sector }\end{array}$} & $\begin{array}{l}\text { Last job in the } \\
\text { public sector }\end{array}$ \\
\hline First job in the private sector & $46.1 \quad(2978)$ & $50.0 \quad(596)$ \\
First job in the public sector & $39.9 \quad(293)$ & $46.0 \quad(494)$
\end{tabular}

Number of respondents in parenthesis. Data source: Wisconsin Longitudinal Study (WLS) of the University of Wisconsin-Madison. Since 1991, the WLS has been supported principally by the National Institute on Aging (AG-9775 and AG21079), with additional support from the Vilas Estate Trust, the National Science Foundation, the Spencer Foundation, and the Graduate School of the University of Wisconsin-Madison. A public use file of data from the Wisconsin Longitudinal Study is available at http://www.ssc.wisc.edu/ wls/data/.

Table 2 reports data from a survey conducted by the Dutch Ministry of the Interior and Kingdom Relations in 2002 of workers who had recently entered or left the public sector in the Netherlands. Our model implies that for lazy workers, the attractive feature of working in the public sector is that the workload is relatively low, either because effort is unverifiable, or because weak incentives are provided. Table 2 lists the percentage of workers moving between the private and the public sector who mentioned workload as one of the three most important reasons to leave their job. Workers who moved from the private sector to the public sector mention workload more often than workers who moved in the opposite direction. The difference is most pronounced for central government and local governments. Education is the main exception. This may be due to the increasing shortage of teachers in The Netherlands during this period (Meesters, 2003), or it may indicate that our model does not apply to all jobs in the public sector. 
Table 2: Percentage of workers moving from the private sector to the public sector and vice versa who mention workload (column 1) and combining work and family life (column 2) as one of the three most important reasons to leave their job (The Netherlands, 2002).

\begin{tabular}{|c|c|c|c|c|c|c|}
\hline \multirow[b]{2}{*}{ Sector } & \multicolumn{2}{|c|}{ Workload } & \multicolumn{2}{|c|}{$\begin{array}{l}\text { Combining work } \\
\text { and family life }\end{array}$} & \multicolumn{2}{|c|}{$\begin{array}{l}\text { Number of } \\
\text { respondents }\end{array}$} \\
\hline & Inflow & Outflow & Inflow & Outflow & Inflow & Outflow \\
\hline Central & 15.8 & 1.5 & 19.0 & 8.3 & 329 & 134 \\
\hline Local & 16.3 & 7.4 & 20.5 & 4.5 & 681 & 267 \\
\hline Police & 9.1 & 2.0 & 10.2 & 8.7 & 444 & 95 \\
\hline Research $^{1}$ & 12.7 & 9.3 & 17.1 & 4.3 & 128 & 31 \\
\hline Hospitals $^{2}$ & 11.0 & 12.9 & 11.9 & 14.3 & 40 & 46 \\
\hline Defence & 3.2 & 4.6 & 9.5 & 34.5 & 159 & 107 \\
\hline Education & 14.5 & 35.0 & 23.4 & 13.3 & 432 & 145 \\
\hline
\end{tabular}

Data source: BZK, Mobiliteitsonderzoek 2002.

1 Research consists of universities and research institutes.

2 Only university hospitals were surveyed.

Another reason for why people may differ in their disutility from work effort is that they face different external constraints. For instance, the care for children or for a sick family member may draw on someone's energy and concentration at work and may raise the opportunity cost of time at work. The second column of Table 2 presents the percentage of workers moving between the private and the public sector who mention combining work and family life as one of the three most important reasons to leave their job. Clearly, people who moved from a private sector job to a public sector job mention combining work and family life relatively often compared to people who moved from the public to the private sector, with defence being an obvious exception. ${ }^{3}$ In Appendix A1, we report the same data as in Table 2 separated by gender. Although there are some differences between the sexes, most notably in research and defence for workload and in the police and hospitals for combining work and family life, the broad pattern of the

\footnotetext{
${ }^{3}$ When we restrict our sample to people who worked full-time at both jobs, the results for workload provide even stronger support for our prediction, and the results for combining work and family life are only slightly weaker.
} 
findings in Table 2 holds for both men and women. ${ }^{4}$

The paper is organised as follows. The next section discusses how the paper relates to the literature. Section 3 describes the model. Section 4 analyses the case where effort is verifiable in both sectors of the economy. In Section 5, effort in the public sector is unverifiable. Section 6 compares our results with the case where the public agency maximises social welfare rather than minimises costs. Section 7 concludes.

\section{Related Literature}

Our paper is related to the Roy model of occupational choice (Roy, 1951). Roy studies workers' self-selection into occupations and the resulting income distribution in a model where workers are heterogeneous in occupationspecific productivity. Jovanovic (1982)'s extension of the Roy model allows a worker's productivity in one sector of the economy to be private knowledge of the worker. As a result of this information asymmetry, the market equilibrium has too many people working in the sector where productivity can not be observed relative to the second-best social optimum. The crowding-out argument we develop in Section 5 is close in spirit to this result. Besides our focus on the public sector and workers' motivation, our analysis differs from both Roy (1951) and Jovanovic (1982) in that worker's effort is endogenous, which leads to interesting issues of contract design in Section 4. Moreover, while the earlier studies assume competitive labor markets, we assume that the public sector has monopsony power over some workers (those with a public service motivation), which gives rise to rent extraction.

Our model is also closely related to the literature on screening of workers' ability initiated by the seminal papers of Spence (1973) and Rothschild and Stiglitz (1976) (for an overview, see Riley, 2001). In a standard adverse selection model (see e.g. Laffont and Martimort, 2002), a firm induces the 'low'-type worker to exert a suboptimally low level of effort, so as to extract more of the rents from the 'high'-type worker. The contract of the 'high'type worker is efficient. In contrast, in our model the contracts of both

\footnotetext{
${ }^{4}$ This is in line with the empirical findings in Benz (2005) which suggest that, even though women are strongly overrepresented in the public sector, there is no gender-specific preference for working in the non-profit sector in the US and the UK. The overrepresentation of women in non-profit firms can largely be explained by non-profit firms' concentration in 'professional services', a sector which mainly employs women.
} 
types are distorted. The reason is that, whereas in the standard model a firm designs contracts for a fixed number of workers, our model describes the behaviour of an agency which has to meet a production requirement. ${ }^{5}$

An important feature of our model is heterogeneity in workers' laziness. This may stem from differences in people's physical fitness or ability, as in the standard adverse selection model, but also from heterogeneity in general work ethic or morale. Differences in work ethic have been associated with, among others, personality traits (Furnham, 1992) and cultural factors (Hofstede, 1991). Caplan (2003) surveys the modern personality psychology literature and concludes that: "Some people are much more eager to shirk than others by showing up late, spending their effort on non-work projects, taking their time, stealing office supplies and so on. Preferences for these sorts of behavior throughout the population markedly differ, holding constraints constant." (p. 398).

A new strand in the economics literature emphasises that workers in public organisations (or, more generally, in non-profit organisations) may be intrinsically motivated to work. For instance, Dixit (2002) argues that organisations that have an idealistic or ethical purpose may be attractive to workers who share these goals. Besley and Ghatak (2005) show that, when workers are protected by limited liability, a good match between an organisation's and a worker's mission reduces the need for high-powered incentives. Francois (2000) and Glazer (2004) develop models where workers intrinsically value the output of the public organisation, see also Preston (1989). In Benabou and Tirole (2003) and Delfgaauw and Dur (2005b), workers may enjoy exerting effort at work or, following Andreoni (1990)'s 'warm glow' assumption, intrinsically value their personal contribution to output. The main difference between our paper and earlier work is that we relax the assumption that types of workers are observed by employers. ${ }^{6}$

Most related to our work is a recent paper by Prendergast (2003). He

\footnotetext{
${ }^{5}$ It is easy to extend our model to allow for price-elastic demand for public goods. Then, as in the case of a production requirement, both contracts are distorted.

${ }^{6}$ This paper builds on previous work. In Delfgaauw and Dur (2005a), we examine the implications of workers' intrinsic motivation for optimal monetary incentive schemes and show that posting a higher wage increases the probability of filling the vacancy, but decreases the expected quality of the hiree as less motivated workers are induced to apply. In Delfgaauw and Dur (2005b), we analyse the consequences of deregulation of a sector previously dominated by a public agency in a model where workers differ in their intrinsic motivation to work in the sector.
} 
assumes that workers differ in altruism for clients and shows that the government prefers to attract different worker types for different agencies. For agencies where the preferences of the government and clients are aligned, as in health care, the government prefers the most altruistic bureaucrats. However, when the preferences of the government and clients are not aligned, as with (suspected) criminals, bureaucrats should be biased against their clients. Prendergast shows that, when agents' types are unobservable, agencies are likely to attract both the most preferred and the least preferred workers. The latter enter the agency because they benefit most from diverting from the government's most preferred policy.

Our work also relates to Lazear (1986). He argues that firms can use their wage policy so as to attract certain types of workers, just like the public agency in our model does. Strong monetary incentives induce highly productive workers to apply at a firm, whereas less productive workers prefer a high base salary and weak incentives (see also Lazear, 1995, and Prendergast, 1999, for surveys). Moen and Rosen (2005) have recently built on this and argue that, when there is a multi-tasking problem, competition between firms for highly productive workers may result in incentives that are too high-powered from a social welfare perspective. Burgess and Metcalfe (1999) show empirically that private companies make far more use of incentive wages than public organisations. Moreover, they argue that there are insufficient grounds to justify the low incentivisation of the public sector. Our model implies that lazy workers indeed receive weaker monetary incentives at the public agency compared to the private sector, and suggests that this may be cost-efficient. On the other hand, dedicated workers get stronger incentives. ${ }^{7}$

A few papers consider heterogeneity in ability among government workers in the context of downsizing the government (Jeon and Laffont, 1999, and Rama, 1999). Jeon and Laffont (1999) show that the optimal voluntary downsizing mechanism consists of a menu of public wages, severance pay, and probabilities of dismissal. The government's choice of which workers to retain closely resembles our results in Section 6, where we impose that the government maximises social welfare. When workers differ in a sector-

\footnotetext{
${ }^{7}$ To empirically test this implication of the model, one clearly needs more detailed data on incentive pay in the public sector than have so far been used in empirical studies. Ideally, career-concern incentives (including those related to job opportunities in the private sector) should also be taken into account.
} 
specific trait, the government prefers the workers who have a comparative advantage in the public sector, whereas when workers differ in a general trait, the government is indifferent. Our paper differs in three important aspects. First, we consider a model in which workers are heterogeneous both in general and in sector-specific productivity, whereas Jeon and Laffont study heterogeneity in general and in sector-specific productivity separately. We show that heterogeneity in sector-specific motivation implies that a cost-minimising government is not indifferent between workers who differ in general work ethic. Second, in their model, effort is fixed, implying that they do not consider optimal incentive schemes. Third, most of our analysis focuses on a cost-minimising government rather than a welfare-maximising government.

\section{The Model}

There are two sectors in the economy, a private sector and a public sector. The private sector is a fully competitive market where workers receive their full marginal product. The public sector is run by a single entity, which can be thought of as the government, and will be referred to as the public agency. We will consider both the case where a worker's effort and output are verifiable in the public sector (Section 4) and the case where effort and output are unverifiable in the public sector (Section 5). A worker's effort in the private sector is assumed to be verifiable throughout the paper.

The private sector and public sector have the same linear production function:

$$
q(e)=e
$$

where $q$ is production and $e$ is effort. Each unit of production of the private sector is sold on the world market for the exogenous price $p$. The public agency produces public goods, which are therefore not priced. The desired amount of public production is given by $Q .{ }^{8}$ First, we assume that the public agency minimises cost of production. Next, we compare the results with a social welfare maximising public agency. We abstract from principal-agent problems between voters, politicians, and managers of the public agency,

\footnotetext{
${ }^{8}$ Price-elastic demand for public goods would not alter any of the results qualitatively. By varying the level of $Q$, our analysis yields the supply function for public goods. Demand and supply then together determine the level of $Q$.
} 
which implies that the objective of the public agency is in line with the interest of (a majority of) the voters.

Three types of workers exist in the economy: regular workers $r$, dedicated workers $m$, and lazy workers $l$. Lazy workers incur a greater disutility from working than the other worker types. Dedicated workers derive intrinsic utility from exerting effort in the public sector, but are otherwise identical to regular workers. ${ }^{9}$ Workers know their own type, but neither private firms nor the public agency can observe a worker's type. Let $N_{i}$ denote the number of workers of type $i$ in the economy and let $n_{i}$ denote the number of workers of type $i$ employed in the public sector, where $i \in\{r, m, l\}$.

The utility of a worker of type $i$ from working in the private sector is given by:

$$
U_{i}=w-\theta_{i} C(e)
$$

where $w$ is the wage, $C(e)$ describes the cost of effort, with properties $C(0)=$ $0, C^{\prime}(\cdot)>0$, and $C^{\prime \prime}(\cdot)>0$, and $\theta_{i}$ measures the degree of laziness. We assume that $0<\theta_{r}=\theta_{m}<\theta_{l}$.

The utility of a worker of type $i$ from working in the public sector is given by: ${ }^{10}$

$$
U_{i}=w+\gamma_{i} V(e)-\theta_{i} C(e)
$$

where $V(e)$ is a concave function with properties $V(0)=0, V^{\prime}(\cdot)>0$ and $V^{\prime \prime}(\cdot)<0$, and $\gamma_{i}$ measures the public service motivation of a worker. We assume that $\gamma_{m}>\gamma_{r}=\gamma_{l}=0$. Hence, only dedicated workers derive utility from exerting effort in the public sector. Dedicated workers have an action-oriented motivation, as in Benabou and Tirole (2003) and Delfgaauw and Dur (2005a, 2005b). Since $q=e$, results are the same if we assume that dedicated workers intrinsically value their personal contribution to the output of the public agency, as in Besley and Ghatak (2005) and Glazer (2004). ${ }^{11}$ As dedicated workers derive motivational utility from effort only

\footnotetext{
${ }^{9}$ Allowing for worker types with an intrinsic motivation for working in the private sector does not change the results, as these workers would seek employment in the public sector only when wages in the public sector are very high.

${ }^{10}$ We assume that workers are employed either in the private or in the public sector. Allowing for part-time jobs in the private sector increases the distortions in the optimal contracts when effort is verifiable. We also abstract from subcontracting, thereby ruling out that a dedicated worker takes over the contracts of multiple lazy or regular workers at the public firm.

${ }^{11}$ This assumption resembles the 'warm glow' assumption introduced by Andreoni (1990). In contrast, Francois (2000) and Prendergast (2003) assume that workers have an
} 
when they work for the public agency, the agency has monopsony power over these workers. ${ }^{12}$

Competition in the private sector ensures that workers in the private sector receive their full marginal product. Hence, using (1), the wage of a worker of type $i$ employed in the private sector is given by $p e_{i}$. From maximising (2) with respect to $e_{i}$ it follows that the optimal level of effort of a worker of type $i$ in the private sector, which we denote by $e_{i}^{*}$, is implicitly given by:

$$
C^{\prime}\left(e_{i}^{*}\right)=\frac{p}{\theta_{i}}
$$

The resulting level of utility of a worker of type $i$ when working in the private sector is:

$$
U_{i}^{*}=p e_{i}^{*}-\theta_{i} C\left(e_{i}^{*}\right)
$$

Note that $U_{i}^{*}$ is decreasing in $\theta_{i}$.

For future reference, we derive the level of effort dedicated workers would exert in the private sector if they would have intrinsic motivation to work in the private sector. This level of effort, denoted by $e_{m}^{x}$, is implicitly given by:

$$
C^{\prime}\left(e_{m}^{x}\right)=\frac{p+\gamma_{m} V^{\prime}\left(e_{m}^{x}\right)}{\theta_{m}}
$$

In the public sector, we distinguish two cases, verifiable effort and unverifiable effort. If effort is verifiable, the public agency offers one or more contracts in which both the level of effort and the wage are specified. In the second case, each worker's effort (and output) in the public sector is unverifiable above a certain level of $e$, which is denoted by $\bar{e} .{ }^{13}$ We assume that $\bar{e}$ is sufficiently small such that it is a binding restriction for lazy and regular workers. This requires that $\bar{e}<e_{l}^{*}$. Then, the public agency can only offer a forcing contract in which a wage level is specified, along with the threat not to pay the wage if effort is below $\bar{e}$.

altruistic motivation, that is, workers care about the provision of public services, but do not derive utility from their personal involvement in production.

${ }^{12}$ Allowing for a fourth type of worker, who derives motivational utility from working in the public sector, but is lazy as well $\left(\gamma=\gamma_{m}, \theta=\theta_{l}\right)$ does not affect the results, unless there are much more lazy dedicated workers than regular dedicated workers and $\gamma_{m}$ is very low compared to $\theta_{l}-\theta_{r}$.

${ }^{13} \bar{e}$ reflects that workers who do not show up at work or remain idle behind their desk most of the day can be detected and are fired. When $\bar{e}=0$, no extrinsic incentives can be provided, implying that public goods production has to rely completely on intrinsic motivation. 
Wages in the public sector are financed through a lump-sum (non-distortionary) tax, uniformly levied on all workers in the economy. This implies that we can ignore taxation when deriving workers' choice of occupation and effort.

\section{Verifiable Effort}

When effort is verifiable, the public agency optimally offers one or more contracts specifying a wage and a required level of effort. Consider first the case where $Q$ is sufficiently small, such that the agency needs only one worker type. Given the type of worker, the optimal contract then minimises

$$
Z=w_{i} n_{i}
$$

with respect to $e_{i}$, subject to the participation constraint

$$
w_{i}=U_{i}^{*}+\theta_{i} C\left(e_{i}\right)-\gamma_{i} V\left(e_{i}\right)
$$

and the production constraint $Q=e_{i} n_{i}$. After some rearrangement, this gives first-order condition:

$$
\left[\theta_{i} C^{\prime}\left(e_{i}\right)-\gamma_{i} V^{\prime}\left(e_{i}\right)\right]-\left[\frac{U_{i}^{*}+\theta_{i} C\left(e_{i}\right)-\gamma_{i} V\left(e_{i}\right)}{e_{i}}\right]=0
$$

In the optimum, the marginal cost of effort of the employed workers (the first term) is equal to the marginal cost of effort by hiring an additional worker (the second term). Using (4) and (5), it is easy to verify that condition (9) is satisfied for lazy workers and for regular workers if $e_{i}=e_{i}^{*}$. Hence, if the public agency chooses to hire lazy or regular workers, it induces them to exert as much effort as they do in the private sector. The participation constraint (8) then implies that the public agency has to pay them the same wage as they earn in the private sector, $p e_{i}^{*}$. When we substitute $e_{m}^{*}$ for $e_{m}$ in equation (9), we find, by using (4) and (5), that condition (9) is not satisfied, since:

$$
-e_{m}^{*} \gamma_{m} V^{\prime}\left(e_{m}^{*}\right)+\gamma_{m} V\left(e_{m}^{*}\right)>0
$$

where the inequality follows from the concavity of $V(e)$. Hence, dedicated workers are induced to exert less effort than in the private sector, even though their intrinsic motivation makes them willing to exert more effort at 
the same wage than in the private sector. The intuition is straightforward. As the marginal rents from motivation of a single worker decrease with $e_{m}$, it is optimal for the public agency to set $e_{m}$ relatively low and attract additional dedicated workers. Thereby, the public agency increases the total rents from motivation generated in the public sector, resulting in lower costs of public goods production. ${ }^{14}$

Comparing the cost per unit of effort for each worker type, it follows that the public agency prefers to hire dedicated workers. When it hires lazy or regular workers, it has to pay as much for their effort as the private sector does, implying that total cost of public goods production are $p Q$. Even if the public agency would let dedicated workers work as hard as they do in the private sector (that is, $e_{m}=e_{m}^{*}$ ), total cost would be lower than $p Q$, namely $p Q-n_{m} \gamma_{m} V\left(e_{m}^{*}\right)$, as the agency can fully extract the rents arising from the dedicated workers' public service motivation. Since the agency optimally sets $e_{m}<e_{m}^{*}$, it follows that total cost are even lower. Clearly, when the public agency offers the optimal contract to attract dedicated workers, lazy and regular workers have no incentive to opt for a public sector job.

Next, consider the case where $Q$ is sufficiently large, such that the public agency needs to hire two worker types. ${ }^{15}$ Still, the agency prefers to hire all of the dedicated workers as they are the only workers who are willing to work for less than $p$ per unit of effort. The interesting question is which worker type the public agency prefers to hire in addition to the dedicated workers. Total cost $Z$ is given by:

$$
Z=w_{m} N_{m}+w_{k} n_{k}
$$

and the production constraint is given by:

$$
e_{m} N_{m}+e_{k} n_{k}=Q
$$

where $k \in\{r, l\}$. To attract and separate the two types, the agency creates two contracts that meet the following conditions. First, the contracts must

\footnotetext{
${ }^{14}$ It is easy to verify that if $V(e)$ would be a linear function, the public agency optimally sets $e_{m}=e_{m}^{*}$

${ }^{15}$ In Appendix A2 we prove that for each case considered in the main text, there exists a level of $Q$ above which it is optimal for the public agency to attract two worker types instead of one. When effort is verifiable, the supply function of public goods displays a kink at this level of $Q$. When effort is unverifiable, the supply function displays a discontinuous jump at this level of $Q$.
} 
meet the participation constraint of both types:

$$
\begin{array}{ll}
I R_{k} & w_{k}-\theta_{k} C\left(e_{k}\right) \geq U_{k}^{*} \\
I R_{m} & w_{m}+\gamma_{m} V\left(e_{m}\right)-\theta_{m} C\left(e_{m}\right) \geq U_{m}^{*}
\end{array}
$$

Second, the contracts must meet the revelation constraints, that is, each worker must prefer the contract designed for his type to the other contract: ${ }^{16}$

$$
\begin{array}{ll}
I C_{k} \quad w_{k}-\theta_{k} C\left(e_{k}\right) \geq w_{m}-\theta_{k} C\left(e_{m}\right) \\
I C_{m} \quad w_{m}+\gamma_{m} V\left(e_{m}\right)-\theta_{m} C\left(e_{m}\right) \geq w_{k}+\gamma_{m} V\left(e_{k}\right)-\theta_{m} C\left(e_{k}\right)
\end{array}
$$

Consider first the case where the public agency decides to attract dedicated and regular workers, $k=r$. This resembles a standard adverse selection problem, where workers differ in their productivity inside the firm, but have the same outside option (since $\theta_{r}=\theta_{m}$ ). As in the standard model, the participation (or Individual Rationality) constraint of the 'low' type and the revelation (or Incentive Compatibility) constraint of the 'high' type are binding, while the other two constraints are non-binding (see e.g. Laffont and Martimort, 2002, chapter 2). Hence, the optimisation problem of the public agency is to minimise cost (10) with respect to $e_{m}$ and $e_{r}$, subject to $I R_{r}, I C_{m}$, and the production constraint (11). This gives the following two first-order conditions for $e_{m}$ and $e_{r}$, respectively:

$$
\begin{gathered}
-\frac{N_{m}}{e_{r}}\left[U_{r}^{*}+\theta_{r} C\left(e_{r}\right)\right]+N_{m}\left[\theta_{m} C^{\prime}\left(e_{m}\right)-\gamma_{m} V^{\prime}\left(e_{m}\right)\right]=0 \\
{\left[e_{r} \theta_{r} C^{\prime}\left(e_{r}\right)-U_{r}^{*}-\theta_{r} C\left(e_{r}\right)\right]\left[\frac{Q-e_{m} N_{m}}{e_{r}^{2}}\right]+N_{m}\left[\gamma_{m} V^{\prime}\left(e_{r}\right)+C^{\prime}\left(e_{r}\right)\left(\theta_{r}-\theta_{m}\right)\right]=0}
\end{gathered}
$$

By substituting $e_{r}=e_{r}^{*}$ into first-order condition (13) and using (4) and (5), the first term drops out. Since the second term is positive, it follows that

\footnotetext{
${ }^{16}$ We assume that workers choose which contract to sign after applying. If a worker had to choose for which contract to apply, dedicated workers would have to take into account that not all workers applying for the contract designed for the other type may get a job, as the number of applications may exceed the number of available jobs. This would weaken $I C_{m}$, and hence further reduce the rents that dedicated workers obtain. Further, we also assume that the public agency can commit not to renegotiate the contracts after the types have been revealed, such that the ratchet effect has no bite.
} 
the public agency induces the regular workers to exert less effort than they do in the private sector, $e_{r}<e_{r}^{*}$. Substituting this result into equation (12), we find that the contract for the dedicated workers is also distorted. The public agency induces the dedicated workers to exert more effort than they would do in the private sector if they would be motivated to work in the private sector, $e_{m}>e_{m}^{x}$.

Intuitively, as in the standard adverse selection model, the public agency makes the contract of the regular workers less attractive to dedicated workers by decreasing the level of effort in that contract. Thereby, it can extract a greater part of the rents from public service motivation from the dedicated workers. However, this decrease in effort implies that the public agency needs to hire more regular workers to meet the production constraint, which is costly. It can decrease these costs by increasing the effort of dedicated workers. In the optimum, the cost of an additional unit of effort by giving stronger incentives to the dedicated workers is equal to the cost of an additional unit of effort by hiring an additional regular worker. ${ }^{17}$

Next, consider the case where the public agency decides to attract dedicated and lazy workers, $k=l$. If the revelation constraint of dedicated workers $I C_{m}$ is binding, the optimisation problem of the public agency is similar to that above, leading to first-order conditions (12) and (13) with $r=l$. Hence, the public agency distorts both contracts by giving lazy workers weaker incentives than private firms do, and by giving dedicated workers stronger incentives than private firms would.

Interestingly, however, when the public agency attracts lazy workers, it is also possible that the revelation constraint does not bind, i.e. that the contract for lazy workers is less appealing to dedicated workers than working in the private sector. ${ }^{18}$ In this case, $I R_{m}$ and $I R_{l}$ are binding, while $I C_{m}$ and $I C_{l}$ are non-binding. Then, the optimisation problem of the public agency is to minimise cost (10) with respect to $e_{m}$ and $e_{l}$, subject to $I R_{l}, I R_{m}$, and the production constraint (11). This gives the following two first-order

\footnotetext{
${ }^{17}$ Allowing for part-time jobs in the private sector makes contract distortions less costly. Regular workers would take a part-time job in the private sector alongside their public sector job, thereby increasing their utility. Hence, the cost of the downward distortion for the public agency is lower, implying that the agency can extract more rents from the dedicated workers.

${ }^{18}$ Note that this can never happen when the public agency hires regular workers rather than lazy workers, since regular and dedicated workers have the same outside option.
} 
conditions for $e_{m}$ and $e_{l}$, respectively:

$$
\begin{gathered}
-\frac{N_{m}}{e_{l}}\left[U_{l}^{*}+\theta_{l} C\left(e_{l}\right)\right]+N_{m}\left[\theta_{m} C^{\prime}\left(e_{m}\right)-\gamma_{m} V^{\prime}\left(e_{m}\right)\right]=0 \\
{\left[e_{l} \theta_{l} C^{\prime}\left(e_{l}\right)-U_{l}^{*}-\theta_{l} C\left(e_{l}\right)\right]\left[\frac{Q-e_{m} N_{m}}{e_{l}^{2}}\right]=0}
\end{gathered}
$$

By substituting $e_{l}=e_{l}^{*}$ and using (4) and (5), we find that the first term between brackets of first-order condition (15) is zero. Hence, the public agency sets the level of effort for the lazy workers equal to their optimal level of effort in the private sector. Obviously, their wage must then also be at the same level as in the private sector. Substituting this result into first-order condition (14) gives $e_{m}=e_{m}^{x}$. Hence, neither contract is distorted and the contract offered to dedicated workers extracts all of their rents (as $I R_{m}$ is binding).

The final step is to show which type of workers the public agency optimally attracts in addition to the dedicated workers. Let us start with the case we just discussed, where the participation constraint of dedicated workers $I R_{m}$ is binding if the agency attracts lazy workers. The public agency pays $p$ per unit of effort to lazy workers and extracts all of the motivational rents from dedicated workers. When, instead, the public agency attracts regular workers, the revelation constraint of the dedicated workers is always binding. Therefore, the public agency can not extract all of the rents from motivation. Moreover, it distorts the contract of the regular workers, implying that the cost per unit of effort of regular workers is greater than $p$. Hence, total cost are lower if the public agency attracts lazy rather than regular workers.

Next, consider the case where the revelation constraint of dedicated workers $I C_{m}$ is binding if the public agency attracts lazy workers. In Appendix A3, we prove that total cost of public goods production $Z$ decrease in the general work ethic of the non-motivated worker type $\theta_{k}, \partial Z / \partial \theta_{k}<0$. Hence, besides dedicated workers, the public agency prefers to attract the economy's laziest workers. The intuition is straightforward. The extraction of motivational rents from dedicated workers by the public agency is hampered by the revelation constraint for dedicated workers $I C_{m}$. To induce dedicated workers to choose the proper contract, they must receive all rents they would obtain by choosing the other type's contract. A con- 
tract satisfying a lazy worker's participation constraint has lower wage and lower required effort than a contract satisfying a regular worker's participation constraint. Therefore, a lazy worker's contract is less appealing to a dedicated worker than a regular worker's contract, implying that the public agency can extract more rents, and hence attracts dedicated workers at lower cost, if it attracts lazy workers rather than regular workers. ${ }^{19}$

It follows that the public agency can produce the same output at lower cost by attracting lazy rather than regular workers. Moreover, the public agency may deliberately provide weak incentives to lazy workers, implying that lazy workers in the public sector exert less effort than lazy workers who are employed in the private sector. The laziness of civil servants may thus be a sign of cost-efficient government!

\section{Unverifiable Effort in the Public Sector}

Next consider the case where effort levels above $\bar{e}$ are unverifiable in the public sector. Then, the best the public agency can do is to offer a forcing contract consisting of a wage which is only paid if the worker exerts at least effort level $\bar{e}$. Clearly, under such a contract, lazy and regular workers never exert more effort than $\bar{e}$. Dedicated workers may decide to exert more effort, which occurs when the level of effort $\widetilde{e}_{m}$ implicitly defined by first-order condition

$$
C^{\prime}\left(\widetilde{e}_{m}\right)=\frac{\gamma_{m} V^{\prime}\left(\widetilde{e}_{m}\right)}{\theta_{m}}
$$

is greater than $\bar{e}$. Substituting (5) and $e_{i}=\bar{e}$ into the participation constraint (8), we find that for lazy and regular workers:

$$
\frac{\partial w_{i}}{\partial \theta_{i}}=\left[p-\theta_{i} C^{\prime}\left(e_{i}^{*}\right)\right] \frac{\partial e_{i}^{*}}{\partial \theta_{i}}-C\left(e_{i}^{*}\right)+C(\bar{e})=-C\left(e_{i}^{*}\right)+C(\bar{e})<0
$$

where the first term between brackets is zero, see first-order condition (4). The inequality follows from the restriction $\bar{e}<e_{i}^{*}$. Hence, when effort is un-

\footnotetext{
${ }^{19}$ In the absence of dedicated workers in the economy, $N_{m}=0$, it follows from firstorder condition (13) that the public agency does not distort the contract of regular or lazy workers. The same is true when the public agency can observe worker types. In both cases, the agency is indifferent between lazy and regular workers, as both are willing to work in the public sector for $p$ per unit of effort. Hence, the contract distortions and the public agency's preference for lazy workers stem from the presence of dedicated workers in conjunction with the unobservability of worker types.
} 
verifiable, the public agency prefers lazy workers to regular workers, because they demand a lower wage. The intuition is that lazy workers value the relatively low level of effort in the public sector more than regular workers. Dedicated workers also need to be paid less than regular workers, but for a different reason. They require a lower wage than regular workers, because they derive motivational utility from working in the public sector. Hence, the public agency also prefers dedicated workers to regular workers, because wage cost are lower and, if $\widetilde{e}_{m}>\bar{e}$, their effort is higher.

Whether the public agency prefers dedicated workers to lazy workers is ambiguous. Dedicated workers may exert more effort and need less monetary compensation for their effort, but have higher opportunity cost of working in the public sector than lazy workers. If $\widetilde{e}_{m} \leq \bar{e}$, then the public agency prefers dedicated workers to lazy workers when $w_{m}<w_{l}$, where $w_{m}$ and $w_{l}$ follow from the participation constraint (8). If $\widetilde{e}_{m}>\bar{e}$, then dedicated workers are preferred when $w_{m} / \widetilde{e}_{m}<w_{l} / \bar{e}$. However, in the latter case, it is possible that the agency prefers to attract only dedicated workers, but that at the wage it has to offer to attract them, lazy workers apply as well. In other words, lazy workers may crowd out dedicated workers in the public sector. This occurs when $w_{l} / \bar{e}>w_{m} / \widetilde{e}_{m}$ and $w_{l}<w_{m}$. Then, setting $w_{m}$ rather than $w_{l}$ is optimal if:

$$
w_{l} / \bar{e}>w_{m} \frac{N_{l}+N_{m}}{N_{l} \bar{e}+N_{m} \widetilde{e}_{m}}
$$

where we assume that when the public agency sets $w_{m}$, each worker of type $l$ and $m$ has equal chance of being hired by the agency, and that the agency sets employment so that expected output equals $Q$. Hence, for a larger range of parameter values, it is optimal to attract lazy workers only. With concave utility from public goods, the condition becomes even more stringent as total public output becomes uncertain when the agency sets $w_{m}$.

Crowding out of dedicated workers may also happen when $Q$ is sufficiently large, such that the public agency would like to attract all of the dedicated workers in the economy and a limited number of lazy workers. Then, as the public agency can not distinguish between lazy and dedicated workers, some of the dedicated workers may not obtain a public sector job. ${ }^{20}$

\footnotetext{
${ }^{20}$ Clearly, when the public agency could observe workers' types, crowding out of dedicated workers would not occur, as contracts could be made contingent on type. This contrasts with the crowding-out arguments by Frey (1997) and Le Grand (2003), which
} 


\section{Social Welfare}

In this section, we impose that the public agency maximises social welfare, which we define as the sum of utilities of all workers in the economy. Recall that, so far, we ignored taxation as our assumption of lump-sum taxes implies that none of the decisions by the workers or the cost-minimising public agency are affected by taxation. However, taxes do affect workers' utility and, hence, social welfare. The total amount of taxes is simply the sum of the wages of the public sector workers $(Z)$. Since utility is linear in income, social welfare can be written as: ${ }^{21}$

$$
\Psi=\sum_{i}\left[\left(N_{i}-n_{i}\right) U_{i}^{*}+n_{i} U_{i}\right]-Z
$$

By using (3) and noting that $Z=\sum_{i} n_{i} w_{i}$, equation (17) can be rewritten to:

$$
\Psi=\sum_{i}\left\{\left(N_{i}-n_{i}\right) U_{i}^{*}+n_{i}\left[-\theta_{i} C\left(e_{i}\right)+\gamma_{i} V\left(e_{i}\right)\right]\right\}
$$

Hence, a welfare-maximising agency maximises total before-tax utility in the private sector minus the net cost of effort in the public sector.

In Appendices A4 and A5, we prove that the optimal choice of a welfaremaximising agency is similar to that of a cost-minimising agency when effort is unverifiable (except for condition (16)), and when effort is verifiable and $Q$ is sufficiently small. Thus, when effort is unverifiable, regular workers are least attractive to the public agency, and lazy and dedicated workers may both be the best choice. When effort is verifiable and $Q$ is sufficiently small, the public agency attracts dedicated workers, and induces them to exert a level of effort which is smaller than private firms do, $e_{m}<e_{m}^{*}$.

When effort is verifiable and $Q$ is sufficiently large, the public agency hires all dedicated workers (as they have lowest net cost of effort in the public sector) and $n_{k}$ workers without public service motivation, implying

are based on the assumption that monetary rewards can directly affect a worker's intrinsic motivation, and also with the crowding-out argument by Benabou and Tirole (2003), which arises from an informational advantage of the employer concerning task characteristics.

${ }^{21}$ Since the public agency's output $Q$ is fixed, we can safely ignore the utility from public goods in the optimisation problem. 
that social welfare (18) can be rewritten as:

$$
\Psi=\sum_{i}\left(N_{i} U_{i}^{*}\right)-n_{k}\left[U_{k}^{*}+\theta_{k} C\left(e_{k}\right)\right]-N_{m}\left[U_{m}^{*}+\theta_{m} C\left(e_{m}\right)-\gamma_{m} V\left(e_{m}\right)\right]
$$

where $k \in\{r, l\}$. Note that (19) neither contains $w_{m}$ nor $w_{k}$. The reason is that utility is linear in income, and so the distribution of income does not affect social welfare. Hence, without affecting social welfare, the public agency sets wages such that the participation constraints $I R_{k}$ and $I R_{m}$ and the revelation constraints $I C_{k}$ and $I C_{m}$ are all satisfied. Maximising (19) with respect to $e_{m}$ and $e_{k}$, subject to the production constraint (11), yields the following first-order conditions for the optimal effort requirements in the contracts:

$$
\begin{gathered}
\frac{N_{m}}{e_{k}}\left[U_{k}^{*}+\theta_{k} C\left(e_{k}\right)\right]-N_{m}\left[\theta_{m} C^{\prime}\left(e_{m}\right)-\gamma_{m} V^{\prime}\left(e_{m}\right)\right]=0 \\
\frac{Q-N_{m} e_{m}}{e_{k}^{2}}\left[U_{k}^{*}+\theta_{k} C\left(e_{k}\right)-e_{k} \theta_{k} C^{\prime}\left(e_{k}\right)\right]=0
\end{gathered}
$$

Using (4) and (5), it follows that first-order condition (21) is zero for $e_{k}=e_{k}^{*}$. Hence, the worker type without public service motivation is induced to exert the same level of effort as in the private sector. Using (5), (11), and (19), this result implies that the public agency is indifferent between hiring lazy and regular workers. Substituting this result into first-order condition (20), it follows that the effort of dedicated workers is (implicitly) given by (6), the level of effort dedicated workers would exert in the private sector if they would derive utility from working there, $e_{m}=e_{m}^{x}$. Hence, a welfaremaximising agency does not distort the contracts of its employees. ${ }^{22}$

The welfare-maximising contracts differ from those offered by the costminimising public agency. This implies that, when the public agency maximises social welfare, social welfare is higher, but also that total cost and, hence, taxes are higher. Apart from the difference in taxes, lazy and regular workers attain the same level of utility, $U_{i}^{*}$, in both cases. Hence, as taxes

\footnotetext{
${ }^{22}$ When the social welfare function is extended to allow for distributional concerns, as in e.g. Boyer and Laffont (2003, Section 6), the public agency may distort contracts. Then, rent extraction from dedicated workers may be considered optimal for distributive reasons. Rent extraction may also be optimal when taxes are distortionary, as in e.g. Laffont and Tirole (1993). Then, the welfare-maximising agency trades off the inefficiencies arising from taxation against the inefficiencies arising from distorting the contracts of its workers.
} 
are higher, welfare-maximisation makes lazy and regular workers worse off. It follows that only dedicated workers benefit from having a social welfare maximising government. Clearly, when dedicated workers constitute a minority in society, politicians are likely to act in the interest of lazy and regular workers and strive for minimum cost of public goods production.

\section{Concluding Remarks}

This paper has shown that, in addition to workers with a public service motivation (dedicated workers), a public agency may prefer to hire the economy's laziest workers and provide them with weaker incentives than the market sector does. Even though this reduces aggregate welfare, a majority of society may be better off, as dedicated workers can be hired at lower wage, and hence public goods are produced at lower cost. When effort is to a large extent unverifiable in the public sector, a public agency may hire too many lazy workers as they crowd out dedicated workers.

Crucial for our main results is the assumption that the public agency has monopsony power over dedicated workers. While this is a plausible assumption in many areas of the public sector, liberalisation and deregulation of markets for public services have most likely reduced the monopsony power of quite some public agencies in a number of countries over the past decades. Empirical studies suggest that these kind of reforms can have important effects on wages. For instance, in Sweden, wages in the health care sector have risen sharply and have become more closely tied to individual performance since private companies began competing with public units (Hjertqvist, 2001). Likewise, several studies have shown that teacher salaries at public schools in the US are significantly higher when public schools face more competition from private schools (Hoxby, 1994, Merrifield, 1999, and Vedder and Hall, 2000) and that under increased competition "less skilled or motivated incumbent teachers might find themselves earning smaller salary increases than some of their peers" (Hoxby, 2002, p. 883). Our model can account for these effects. When, instead of a single public agency which hires all dedicated workers, several agencies compete for dedicated workers, the agencies bid up the wage until dedicated workers earn their full marginal product. Hence, in line with the evidence, dedicated workers earn more and their wage better reflects their performance when agencies compete. Two 
further implications are that, since competition eliminates rent extraction, agencies neither have a reason to provide weak incentives to workers without a public service motivation, nor do they have a strict preference for lazy workers over regular workers. Hence, when agencies compete, regular workers may find their way to the sector and, as a result of stronger incentives, the wage of lazy workers in the public sector is also higher and more closely tied to individual performance. ${ }^{23}$ This selection effect of competition as well as the effect on incentives may account for part of the productivity increase often observed after liberalisation and deregulation of markets for public services (see Hoxby, 1994 and 2000, and Rapp, 2000, on education and Megginson and Netter, 2001, and Kikeri and Nellis, 2002, for broad surveys of the empirical literature).

We have restricted $Q$ such that two worker types are sufficient. It is a straightforward repetition of the analysis to allow for values of $Q$ such that the public agency needs all three worker types. When the difference in general work ethic $\theta$ between lazy and regular workers is sufficiently large, the contract for lazy workers is not distorted, whereas the public agency distorts the contracts for dedicated and regular workers. Otherwise, the contract for lazy workers will be distorted as well. In the limit, when $Q \rightarrow \infty$, the public agency does not distort any contract, as can be seen from first-order condition (13). The reason is that, when the agency needs a great number of workers without a public service motivation, the costs of distorting their contracts are large compared to the benefits of rent extraction from the dedicated workers.

We have abstracted from social interactions between workers. Work morale, however, may be affected by the behaviour of one's colleagues. The enthusiasm of coworkers may be stimulating, whereas shirking colleagues may reduce the incentive to work (Stowe, 2002). Likewise, dedicated workers may consider the wage paid to lazy workers to be unfair given the difference in effort. For both reasons, attracting lazy workers may be detrimental to the effort of dedicated workers. Further, if the pace of production depends on the 'weakest link', it may not be optimal to hire lazy workers.

\footnotetext{
${ }^{23}$ See our related paper (Delfgaauw and Dur, 2005b) for a more detailed discussion of these effects.
} 


\section{A Appendices}

\section{A.1 Table 2 separated by gender}

See next page.

\section{A.2 Conditions under which hiring two types of workers is optimal}

\section{Verifiable effort in the public sector}

First, consider the case where the participation constraint of dedicated workers $I R_{m}$ binds when the public agency attracts lazy workers, while the revelation constraint $I C_{m}$ is non-binding. Marginal cost of effort when hiring a lazy worker is $p$. This implies that the public agency hires lazy workers as soon as the marginal cost of effort of dedicated workers exceeds $p$. Differentiating the participation constraint (8) of dedicated workers with respect to $e_{m}$ gives:

$$
\frac{\partial w_{m}}{\partial e_{m}}=\theta_{m} C^{\prime}\left(e_{m}\right)-\gamma_{m} V^{\prime}\left(e_{m}\right)
$$

Hence, the public agency attracts a second worker type when $Q>N_{m} e_{m}^{\xi}$, where $e_{m}^{\xi}$ is defined by:

$$
\theta_{m} C^{\prime}\left(e_{m}^{\xi}\right)-\gamma_{m} V^{\prime}\left(e_{m}^{\xi}\right)=p
$$

Note that (A2) is identical to (6). Hence, $e_{m}^{\xi}=e_{m}^{x}$, which is the optimal level of effort dedicated workers would exert in the private sector if they would derive utility from working in the private sector.

Next, consider the case where the revelation constraint of dedicated workers $I C_{m}$ binds when the public agency attracts lazy workers, while the participation constraint $I R_{m}$ is non-binding. It is obvious that the public agency attracts only dedicated workers when $Q \leq N_{m} e_{m}^{\xi}$. Now consider higher levels of $Q$. When the agency does not attract lazy workers, total cost can be found by substituting the production constraint $Q=N_{m} e_{m}$ and the participation constraint (8) of dedicated workers into total cost $Z_{1}=N_{m} w_{m}$ :

$$
Z_{1}=N_{m}\left[U_{m}^{*}+\theta_{m} C\left(\frac{Q}{N_{m}}\right)-\gamma_{m} V\left(\frac{Q}{N_{m}}\right)\right]
$$




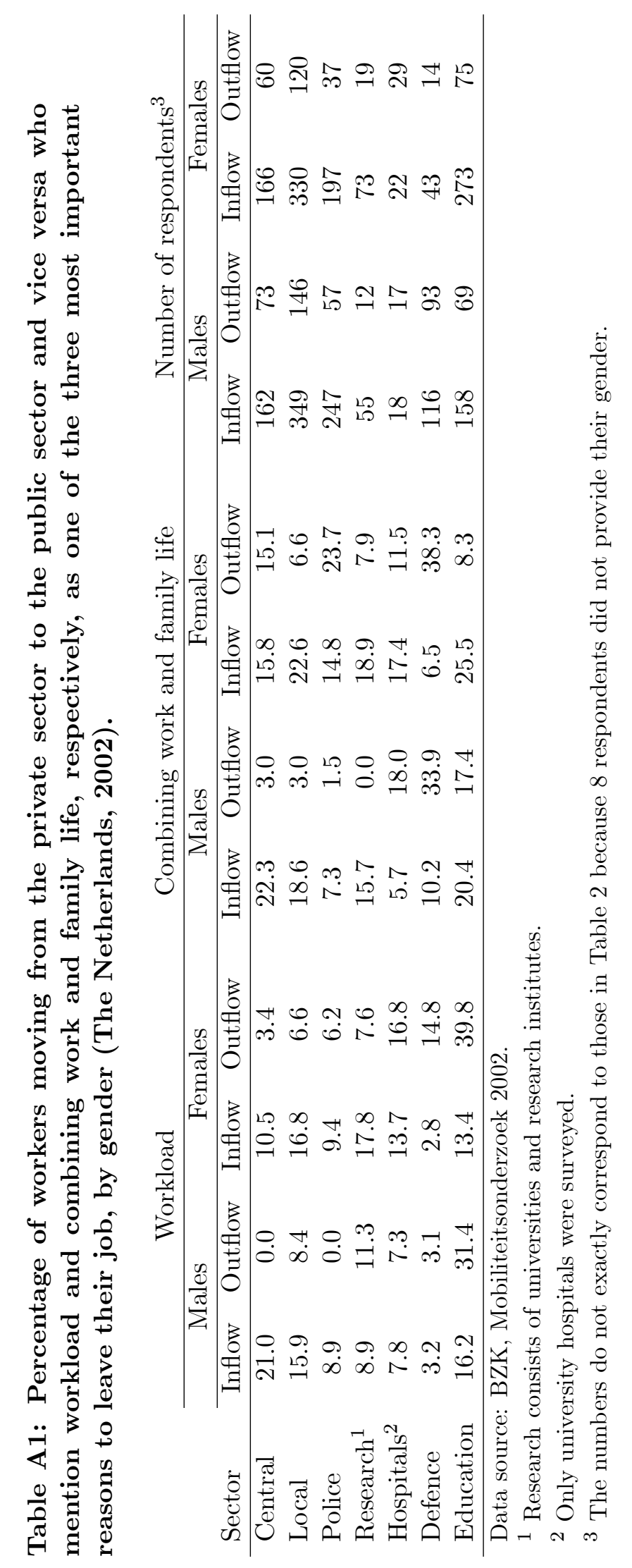


It is easy to verify that $Z_{1}$ is a continuous and convex function of $Q$. When the public agency attracts both dedicated and lazy workers, the public agency can no longer extract all motivational rents from the dedicated workers. Suppose the public agency would not distort the contracts of its workers, $e_{l}=e_{l}^{*}$ and $e_{m}=e_{m}^{\xi}\left(=e_{m}^{x}\right)$. Then, total cost when the public agency attracts both lazy and dedicated workers, $Z_{2}$, is a linear function of $Q$, as the marginal cost of effort equals $p$. Hence, $Z_{1}$ and $Z_{2}$ intersect at some level of $Q>N_{m} e_{m}^{\xi}$. Since the public agency optimally distorts the contracts of its workers when it attracts both lazy and dedicated workers so as to decrease cost, the minimum level of $Q$ at which it is optimal to attract lazy workers is smaller than the level at which $Z_{1}$ and $Z_{2}$ intersect.

\section{Unverifiable effort in the public sector}

Because the public agency can not induce workers to exert a certain level of effort, it is necessary to attract a second worker type as soon as $Q>N_{i} e_{i}$, where $i$ is the worker type the agency prefers to employ when $Q$ is sufficiently low. As argued in the main text, it might happen that the public agency can not single out its most preferred type. Then, the public agency always employs two worker types.

\section{Maximisation of social welfare}

When effort is verifiable, the marginal welfare loss of a unit of effort when hiring workers without a public service motivation is $p$, while it equals $-\theta_{m} C^{\prime}\left(e_{m}\right)+\gamma_{m} V^{\prime}\left(e_{m}\right)$ when hiring dedicated workers only. Hence, a welfare-maximising agency hires a second type of worker when $Q>N_{m} e_{m}^{\xi}$ where $e_{m}^{\xi}$ is defined by (A2). In the case of unverifiable effort, hiring a second worker type is inevitable when $Q>N_{i} e_{i}$ (where $i$ is the worker type the agency prefers to employ when $Q$ is sufficiently low) and when the agency can not single out its most preferred type.

\section{A.3 Proof that $\frac{\partial Z}{\partial \theta_{k}}<0$}

By substituting the production constraint (11), $I R_{k}, I C_{m}$, and (5) into total cost (10), we find:

$$
\begin{aligned}
Z= & \left\{p e_{k}^{*}-\theta_{k}\left[C\left(e_{k}^{*}\right)-C\left(e_{k}\right)\right]\right\}\left(\frac{Q-e_{m} N_{m}}{e_{k}}+N_{m}\right)+ \\
& N_{m}\left\{\theta_{m}\left[C\left(e_{m}\right)-C\left(e_{k}\right)\right]-\gamma_{m}\left[V\left(e_{m}\right)-V\left(e_{k}\right)\right]\right\}
\end{aligned}
$$


A marginal increase in $\theta_{k}$ leads to a decrease in $Z$ :

$$
\frac{\partial Z}{\partial \theta_{k}}=-\left[C\left(e_{k}^{*}\right)-C\left(e_{k}\right)\right]\left(\frac{Q-e_{m} N_{m}}{e_{k}}+N_{m}\right)<0
$$

where, by the envelop theorem, all effects through $e_{k}^{*}, e_{k}$, and $e_{m}$ are zero, and the sign follows from $e_{k}<e_{k}^{*}$ (see first-order condition (13)).

\section{A.4 Proof that cost-minimisation and welfare-maximisation yield similar results when effort is unverifiable}

A cost-minimising public agency attracts the worker type that minimises $Z=n_{i} w_{i}$. After substituting the production constraint $n_{i}=Q / e_{i}$ and (8), we find that:

$$
Z=\frac{Q}{e_{i}}\left[U_{i}^{*}+\theta_{i} C\left(e_{i}\right)-\gamma_{i} V\left(e_{i}\right)\right]
$$

A welfare-maximising public agency attracts the worker type that maximises (18). After substituting the production constraint $n_{i}=Q / e_{i}$, we find that:

$$
\Psi=\sum_{i}\left(N_{i} U_{i}^{*}\right)+\frac{Q}{e_{i}}\left[-U_{i}^{*}-\theta_{i} C\left(e_{i}\right)+\gamma_{i} V\left(e_{i}\right)\right]
$$

Obviously, since $\sum_{i}\left(N_{i} U_{i}^{*}\right)$ is exogenously given, minimisation of $Z$ and maximisation of $\Psi$ result in the same optimal worker type. The only difference lies in the response to the crowding-out problem. While a welfaremaximising agency sets $w_{m}$ when $w_{m} / \widetilde{e}_{m}<w_{l} / \bar{e}$, a cost-minimising agency only does so when condition (16) is satisfied.

\section{A.5 Proof that cost-minimisation and welfare-maximisation yield similar results when effort is verifiable and $Q$ is sufficiently small}

A welfare-maximising public agency maximises (18) with respect to $e_{i}$, subject to the production constraint $n_{i}=Q / e_{i}$. This gives first-order condition:

$$
-\left[\theta_{i} C^{\prime}\left(e_{i}\right)-\gamma_{i} V^{\prime}\left(e_{i}\right)\right]+\left[\frac{U_{i}^{*}+\theta_{i} C\left(e_{i}\right)-\gamma_{i} V\left(e_{i}\right)}{e_{i}}\right]=0
$$

which is, except for opposite signs, identical to first-order condition (9) derived in Section 4. Hence, the optimal contract of a welfare-maximising public agency is identical to that of a cost-minimising public agency. 


\section{References}

[1] Andreoni, James (1990), Impure Altruism and Donations to Public Goods: A Theory of Warm-Glow Giving, Economic Journal, vol. 100 (401), pp. 464-477.

[2] Antonazzo, Emanuela, Scott, Anthony, Skatun, Diane, and Elliot, Robert F. (2003), The Labour Market for Nursing: A Review of the Labour Supply Literature, Health Economics, vol. 12 (6), pp. 465-478.

[3] Benabou, Roland, and Tirole, Jean (2003), Intrinsic and Extrinsic Motivation, Review of Economic Studies, vol. 70 (3), pp. 489-520.

[4] Benz, Matthias (2005), Not for the Profit, but for the Satisfaction? Evidence on Worker Well-Being in Non-Profit Firms, Kyklos, vol. 58 (2), pp. 155-176.

[5] Besley, Timothy and Ghatak, Maitreesh (2005), Competition and Incentives with Motivated Agents, American Economic Review, vol. 95 (3), pp. 616-636.

[6] Boyer, Marcel, and Laffont, Jean-Jacques (2003), Competition and the Reform of Incentive Schemes in the Regulated Sector, Journal of Public Economics, vol. 87 (9-10), pp. 2369-2396.

[7] Buchanan, James M. (1978), The Economics of Politics, London: Institute of Economic Affairs.

[8] Burgess, Simon, and Metcalfe, Paul (1999), The Use of Incentive Schemes in the Public and Private Sectors: Evidence from British Establishments, CMPO Working Paper 99/015.

[9] Caplan, Bryan (2003), Stigler-Becker versus Myers-Briggs: why preference-based explanations are scientifically meaningful and empirically important, Journal of Economic Behavior and Organization, vol. 50 (4), pp. 391-405.

[10] Delfgaauw, Josse, and Dur, Robert (2005a), Signaling and Screening of Workers' Motivation, Journal of Economic Behavior and Organization, forthcoming. 
[11] Delfgaauw, Josse, and Dur, Robert (2005b), From Public Monopsony to Competitive Market: More Efficiency but Higher Prices, Tinbergen Institute Discussion Paper 02-118/1.

[12] Dixit, Avinash (2002), Incentives and Organizations in the Public Sector: An Interpretative Review, Journal of Human Resources, vol. 37 (4), pp. 696-727.

[13] Downs, Anthony (1967), Inside Bureaucracy, Boston: Little, Brown.

[14] Edmonds, Suzanne, Sharp, Caroline, and Benefield, Pauline (2002), Recruitment to and Retention on Initial Teacher Training - A Systematic Review, Slough: National Foundation for Educational Research.

[15] Francois, Patrick (2000), 'Public Service Motivation' as an Argument for Government Provision, Journal of Public Economics, vol. 78 (3), pp. 275-299.

[16] Frank, Sue A., and Lewis, Gregory B. (2004), Government Employees: Working Hard or Hardly Working?, American Review of Public Administration, vol. 34 (1), pp. 36-51.

[17] Frey, Bruno S. (1997), On the Relationship Between Intrinsic and Extrinsic Work Motivation, International Journal of Industrial Organization, vol. 15 (4), pp. 427-439.

[18] Furnham, A. (1992), Personality at Work, London: Routledge.

[19] Glazer, Amihai (2004), Motivating Devoted Workers, International Journal of Industrial Organization, vol. 22 (3), pp. 427-440.

[20] Goodsell, Charles T. (1985), The Case for Bureaucracy: A Public Administration Polemic, 2nd ed. Chatham: Chatham House.

[21] Hjertqvist, Johan (2001), Swedish Health-Care Reform: From Public Monopolies to Market Services, mimeo, Montreal Economic Institute.

[22] Hofstede, Geert (1991), Cultures and Organisations: Software of the Mind, Berkshire: McGraw-Hill Book Company.

[23] Hoxby, Caroline M. (1994), Do Private School Provide Competition for Public Schools?, NBER Working Paper no. 4978. 
[24] Hoxby, Caroline M. (2000), Does Competition Among Public Schools Benefit Students and Taxpayers?, American Economic Review, vol. 90 (5), pp. 1209-1238.

[25] Hoxby, Caroline M. (2002), Would School Choice Change the Teaching Profession?, Journal of Human Resources, vol. 37 (4), pp. 846-891.

[26] Jeon, Doh-Shin, and Laffont, Jean-Jacques (1999), The Efficient Mechanism for Downsizing the Public Sector, World Bank Economic Review, vol. 13 (1), pp. 67-88.

[27] Johnson, William R. (1978), A Theory of Job Shopping, Quarterly Journal of Economics, vol. 92 (2), pp. 261-277.

[28] Jovanovic, Boyan (1979), Job Matching and the Theory of Turnover, Journal of Political Economy, vol. 87 (5), pp. 972-990.

[29] Jovanovic, Boyan (1982), Favorable Selection with Asymmetric Information, Quarterly Journal of Economics, vol. 97 (3), pp. 535-539.

[30] Katz, Daniel, Gutek, Barbara A., Kahn, Robert L., and Barton, Eugenia (1975), Bureaucratic Encounters: A Pilot Study in the Evaluation of Government Services, Ann Arbor: Survey Research Centre, Institute for Social Research, University of Michigan.

[31] Kikeri, Sunita, and Nellis, John, (2002), Privatisation in Competitive Sectors: The Record To Date, World Bank Policy Research Working Paper 2860.

[32] Laffont, Jean-Jacques and Martimort, David (2002), The Theory of Incentives, Princeton: Princeton University Press.

[33] Laffont, Jean-Jacques, and Tirole, Jean (1993), A Theory of Incentives in Procurement and Regulation, Cambridge, MA: MIT Press.

[34] Lazear, Edward P. (1986), Salaries and Piece Rates, Journal of Business, vol. 59 (3), pp. 405-431.

[35] Lazear, Edward P. (1995), Personnel Economics, Cambridge, MA: MIT Press. 
[36] Le Grand, Julien (2003), Motivation, Agency, and Public Policy; Of Knights and Knaves, Pawns and Queens, Oxford: Oxford University Press.

[37] Meesters, Marion (2003), Attracting, Developing, and Retaining Effective Teachers; Country Background Report for The Netherlands, Paris: OECD.

[38] Megginson, William L., and Netter, Jeffrey M. (2001), From State to Market: A Survey of Empirical Studies on Privatization, Journal of Economic Literature, vol. 39 (June), pp. 321-389.

[39] Merrifield, John (1999), Monopsony Power in the Market for Teachers: Why Teachers Should Support Market-Based Education Reform, Journal of Labor Research, vol. 20 (3), pp. 377-391.

[40] Moen, Espen R., and Rosén, Åsa (2005), Performance Pay and Adverse Selection, Scandinavian Journal of Economics, vol. 107 (2), pp. 279-298.

[41] Niskanen, William A. (1971), Bureaucracy and Representative Government, Chicago: Aldine-Atherton.

[42] Prendergast, Canice (1999), The Provision of Incentives in Firms, Journal of Economic Literature, vol. 37 (1), pp. 7-63.

[43] Prendergast, Canice (2003), The Motivation and Bias of Bureaucrats, American Economic Review, forthcoming.

[44] Preston, Anne E. (1989), The Nonprofit Worker in a For-Profit World, Journal of Labor Economics, vol. 7 (4), pp. 438-463.

[45] Rama, Martin (1999), Public Sector Downsizing: An Introduction, World Bank Economic Review, vol. 13 (1), pp. 1-22.

[46] Rapp, Geoffrey C. (2000), Agency and Choice in Education: Does School Choice Enhance the Work Effort of Teachers?, Education Economics, vol. 8 (1), pp. 37-63.

[47] Riley, John G. (2001), Silver Signals: Twenty-Five Years of Screening and Signaling, Journal of Economic Literature, vol. 39 (2), pp. 432-478. 
[48] Rothschild, Micheal, and Stiglitz, Joseph (1976), Equilibrium in Competitive Insurance Markets: An Essay on the Economics of Imperfect Information, Quarterly Journal of Economics, vol. 90 (4), pp. 629-649.

[49] Roy, A.D. (1951), Some Thoughts on the Distribution of Earnings, Oxford Economic Papers, vol. 3 (2), pp. 135-146.

[50] Spence, A.M. (1973), Job Market Signaling, Quarterly Journal of Economics, vol. 90 (3), pp. 355-374.

[51] Stowe, Jill (2002), Incorporating Morale into a Classical Agency Model: The Effect of Morale on Incentives and Effort, mimeo, Duke University.

[52] Tullock, Gordon (1965), The Politics of Bureaucracy, Washington: Public Affairs Press.

[53] Vedder, Richard, and Hall, Joshua (2000), Private School Competition and Public School Teacher Salaries, Journal of Labor Research, vol. 21 (1), pp. 161-168.

[54] Wilson, James Q. (1989), Bureaucracy: What Government Agencies Do and Why They Do It, New York: Basic Books. 